\title{
Erratum: Analytic Form of the Two-Loop Planar \\ Five-Gluon All-Plus-Helicity Amplitude in QCD \\ [Phys. Rev. Lett. 116, 062001 (2016)]
}

T. Gehrmann, J. M. Henn, and N. A. Lo Presti

(Received 13 April 2016; published 2 May 2016)

DOI: 10.1103/PhysRevLett.116.189903

Equation (9) of our original Letter published contains a misprint. The corrected equation is

$$
F_{5}^{(2)}=\frac{5 \pi^{2}}{12} F_{5}^{(1)}+\sum_{i=0}^{4} \sigma^{i}\left\{\frac{v_{5} \operatorname{tr}\left[\left(1-\gamma_{5}\right) \not \not_{4} \not \not_{5} \not \not_{1} \not \not_{2}\right]}{\left(v_{2}+v_{3}-v_{5}\right)} I_{23,5}+\frac{1}{6} \frac{\operatorname{tr}\left[\left(1+\gamma_{5}\right) \not \not_{4} \not \not_{5} \not \not_{1} \not \not_{2}\right]^{2}}{v_{1} v_{4}}+\frac{10}{3} v_{1} v_{2}+\frac{2}{3} v_{1} v_{3}\right\} .
$$

This is in agreement with Ref. 1. This misprint does not affect any of the central results of our original Letter.

[1] D. C. Dunbar and W. B. Perkins, arXiv:1603.07514. 